\title{
A Pilot Study of the Effectiveness of Indoor Plants for Removal of Volatile Organic Compounds in Indoor Air in a Seven-Story Office Building
}

\author{
Michael G. Apte ${ }^{1}$ and Joshua S. Apte ${ }^{2}$ \\ ${ }^{1}$ Lawrence Berkeley National Laboratory \\ Environmental Energy Technologies Division \\ Indoor Environment Department \\ Berkeley, CA 94720 \\ ${ }^{2}$ Energy Resources Group \\ University of California, Berkeley \\ Berkeley, CA 94720
}

April 272010

This work was sponsored by the Assistant Secretary for Energy Efficiency and Renewable Energy, Office of Building Technology, State, and Community Programs, of the U.S. Department of Energy under Contract No. DE-AC02-05CH11231. Its contents are solely the responsibility of the authors and do not necessarily represent the official views of the US DOE. 


\section{Introduction}

The Paharpur Business Centre and Software Technology Incubator Park (PBC) is a 7 story, 50,400 $\mathrm{ft}^{2}$ office building located near Nehru Place in New Delhi India. The occupancy of the building at full normal operations is about 500 people. The building management philosophy embodies innovation in energy efficiency while providing full service and a comfortable, safe, healthy environment to the occupants. Provision of excellent Indoor Air Quality (IAQ) is an expressed goal of the facility, and the management has gone to great lengths to achieve it. This is particularly challenging in New Delhi, where ambient urban pollution levels rank among the worst on the planet.

The approach to provide good IAQ in the building includes a range of technical elements: air washing and filtration of ventilation intake air from rooftop air handler, the use of an enclosed rooftop greenhouse with a high density of potted plants as a bio-filtration system, dedicated secondary HVAC/air handling units on each floor with re-circulating high efficiency filtration and UVC treatment of the heat exchanger coils, additional potted plants for bio-filtration on each floor, and a final exhaust via the restrooms located at each floor. The conditioned building exhaust air is passed through an energy recovery wheel and chemisorbent cartridge, transferring some heat to the incoming air to increase the HVAC energy efficiency. The management uses "green" cleaning products exclusively in the building. Flooring is a combination of stone, tile and "zero VOC" carpeting. Wood trim and finish appears to be primarily of solid sawn materials, with very little evidence of composite wood products. Furniture is likewise in large proportion constructed from solid wood materials. The overall impression is that of a very clean and well-kept facility. Surfaces are polished to a high sheen, probably with wax products. There was an odor of urinal cake in the restrooms. Smoking is not allowed in the building.

The plants used in the rooftop greenhouse and on the floors were made up of a number of species selected for the following functions: daytime metabolic carbon dioxide $\left(\mathrm{CO}_{2}\right)$ absorption, nighttime metabolic $\mathrm{CO}_{2}$ absorption, and volatile organic compound (VOC) and inorganic gas absorption/removal for air cleaning. The building contains a reported 910 indoor plants. Daytime metabolic species reported by the PBC include Areca Palm, Oxycardium, Rubber Plant, and Ficus alii totaling 188 plants (21\%). The single nighttime metabolic species is the Sansevieria with a total of 28 plants (3\%). The "air cleaning" plant species reported by the PBC include the Money Plant, Aglaonema, Dracaena Warneckii, Bamboo Palm, and Raphis Palm with a total of 694 plants (76\%). The plants in the greenhouse (Areca Palm, Rubber Plant, Ficus alii, Bamboo Palm, and Raphis Palm) numbering 161 (18\%) of those in the building are grown hydroponically, with the room air blown by fan across the plant root zones. The plants on the building floors are grown in pots and are located on floors 1-6.

We conducted a one-day monitoring session in the PBC on January 1, 2010. The date of the study was based on availability of the measurement equipment that the researchers had shipped from Lawrence Berkeley National Lab in the U.S.A. The study date was not 
optimal because a large proportion of the regular building occupants were not present being New Year's Day. An estimated 40 people were present in the building all day during January 1. This being said, the building systems were in normal operations, including the air handlers and other HVAC components. The study was focused primarily on measurements in the Greenhouse and $3^{\text {rd }}$ and $5^{\text {th }}$ floor environments as well as rooftop outdoors. Measurements included a set of volatile organic compounds (VOCs) and aldehydes, with a more limited set of observations of indoor and outdoor particulate and carbon dioxide concentrations. Continuous measurements of Temperature (T) and relative humidity $(\mathrm{RH})$ were made selected indoor and outdoor locations.

\section{Methods}

Air sampling stations were set up in the Greenhouse, Room 510, Room 311, the $5^{\text {th }}$ and $3^{\text {rd }}$ floor air handler intakes, the building rooftop HVAC exhaust, and an ambient location on the roof near the HVAC intake. VOC and aldehyde samples were collected at least once at all of these locations. Both supply and return registers were sampled in rooms 510 and 311. As were a greenhouse inlet register from the air washer and outlet register ducted to the building's floor level.

Air samples for VOCs were collected and analyzed following the U.S. Environmental Protection Agency (USEPA) Method TO-17 (USEPA, 1999a). Integrated air samples with a total volume of approximately $2 \mathrm{~L}$ were collected at the sites, at a flow rate of $<70$ $\mathrm{cc} / \mathrm{min}$ onto preconditioned multibed sorbent tubes containing Tenax-TA backed with a section of Carbosieve. The VOCs were desorbed and analyzed by thermodesorption into a cooled injection system and resolved by gas chromatography. The target chemicals, listed in Table 1, were qualitatively identified on the basis of the mass spectral library search, followed by comparison to reference standards. Target chemicals were quantified using multipoint calibrations developed with pure standards and referenced to an internal standard. Sampling was conducted using Masterflex L/S HV-07553-80 peristaltic pumps assembled with quad Masterflex L/S Standard HV-07017-20 pump heads.

Concentrations of formaldehyde, acetaldehyde, and acetone were determined following U.S. Environmental Protection Agency (USEPA) Method TO-11a (USEPA, 1999b). Integrated samples $(<60 \mathrm{~L})$ were collected by drawing air through silica gel cartridges coated with 2,4-dinitrophenylhydrazine at a flow rate of $1 \mathrm{Lpm}$. Samples utilized an ozone scrubber cartridge installed upstream from the sample cartridge. Sample cartridges were eluted with $2 \mathrm{~mL}$ of high purity acetonitrile and analyzed by high-performance liquid chromatography (HPLC) with UV detection and quantified with a multipoint calibration for each derivitized target aldehyde. Sampling was conducted using Masterflex L/S HV-07553-71 peristaltic pumps assembled with dual Masterflex L/S Standard HV-07016-20 pump heads.

Continuous measurements of $\mathrm{PM}_{2.5}$ using TSI Dustrak model 8520 monitors were made in Room 510 and at the rooftop-sampling site from about 13:30 to 16:30 of the sampling day. The indoor particle monitor was located on a desk in room 510 and the outdoor monitor was located on a surface elevated above the roof deck. 
Carbon dioxide spot measurements of about 10-minute duration were made throughout the building during the afternoon using a portable data logging real-time infrared monitor (PP Systems model EGM-4A).

Temperature and RH were monitored in the Greenhouse, room 510 and room 311 using Onset model HOBO U12-011 data loggers (Pocasset MA) at one-minute recording rates. Outdoor T and RH were not monitored.

\section{Results}

\section{VOCs and Aldehydes}

The measured VOC concentrations as well as their limits of quantitation (LOQ) by the measurement methods are shown in Table 2. Figures 1-6 show bar graphs of these VOCs. Unless otherwise shown, all measured compounds were above the minimum detection level, but not all measurements were above the LOQ. Those measurements with concentrations below the LOQ should be considered approximations. These air contaminants are organized by possible source categories including: carbonyl compounds that can be odorous or irritating; compounds that are often emitted by building cleaning products; those associated with bathroom products; those often found emitted from office products, supplies, materials, occupants, and in ambient air; those found from plant and wood materials as well as some cleaning products; and finally plasticizers commonly emitted from vinyl and other flexible or resilient plastic products. The groupings in this table are for convenience; many of the listed compounds have multiple sources so the attribution provided may be erroneous.

\section{Carbonyl Compounds}

The carbonyl compounds include formaldehyde that can be emitted from composite wood materials, adhesives, and indoor chemical reactions; acetaldehyde from building materials and indoor chemistry; acetone from cleaners and other solvents. Benzaldehyde sources can include plastics, dyes, fruits, and perfumes. Hexanal, nonanal, and octanal can be emitted from engineered wood products. For many of these compounds, outdoor air can also be a major source. Formaldehyde and acetone were the most abundant carbonyl compounds observed in the PBC. For context, the California 8-h and chronic non-cancer reference exposure level (REL) for formaldehyde is $9 \mu \mathrm{g} \mathrm{m}^{-3}$ and the acute REL is $55 \mu \mathrm{g} \mathrm{m}^{-3}$ (OEHHA 2008). The 60 minute average formaldehyde concentrations observed in the PBC exceeded the REL by up to a factor of three. Acetone has low toxicity and the observed levels were orders of magnitude lower than concentrations of health concern.

Hexanal, nonanal, and octanal are odorous compounds at low concentrations; odor thresholds established for them are $0.33 \mathrm{ppb}, 0.53 \mathrm{ppb}$, and $0.17 \mathrm{ppb}$, respectively (Cometto-Muñiz and Abraham, 2010). Average concentrations observed within the PBC building were $3.8 \pm 0.8 \mathrm{ppb}, 3.5 \pm 0.6 \mathrm{ppb}$, and $1.4 \pm 0.2 \mathrm{ppb}$, for these compounds, respectively, roughly ten times higher than the odor thresholds. Concentrations of these compounds in the supply air from the greenhouse were substantially lower, although still 
in excess of the odor thresholds. The concentration of hexanal and nonanal roughly doubled the ambient concentrations as the outside air passed through the greenhouse. Octanal concentrations were roughly similar in the ambient air and in the air exiting the greenhouse.

\section{Cleaning Solvent Compounds}

Concentrations of benzene, d-limonene, n-hexane, naphthalene and toluene all increased in the greenhouse air in either the AM or PM measurements. The measured levels of these compounds were far below any health relevant standards, although naphthalene concentrations reached close to $50 \%$ of the California REL of $9 \mu \mathrm{g} \mathrm{m}^{-3}$ (OEHHA 2008). The concentrations of these compounds were generally somewhat higher indoors relative to the greenhouse concentrations. The concentration of toluene in the building exhaust was $120 \mu \mathrm{g} \mathrm{m}^{-3}$, more than double the highest level measured indoors, suggesting a possible toluene source in the restrooms. The cleaning compound 2-butoxyethanol was slightly higher indoors, but at very low concentrations. Similar for trichloroethylene that was observed at extremely low levels indoors.

\section{Bathroom Products}

1,4-dichlorobenzene is a common deodorizer and is the primary component in urinal cake. The concentration of this compound appears to increase as the ventilation air travels through the building; about 5-6 $\mu \mathrm{g} \mathrm{m}^{-3}$ in the greenhouse exit air, about $20-25$ $\mu \mathrm{g} \mathrm{m}^{-3}$ on floor 3 , and $50-65 \mu \mathrm{g} \mathrm{m}^{-3}$ on floor 5 . The levels increased dramatically in the building exit stream, reaching $170 \mu \mathrm{g} \mathrm{m}^{-3}$. It is not a surprise that this compound is measured in the exhaust of the building since this air stream flows through the restrooms. It appears that there may be more entrainment of bathroom air into the fifth floor than on the third floor. 1,4-dichlorobenzene has a chronic REL of $800 \mu \mathrm{g} \mathrm{m}^{-3}$, substantially higher than the highest level observed in this study (OEHHA, 2008).

\section{Office products, Supplies, Materials, Occupants, Ambient air}

The compounds listed in this category have many sources, including outdoor air. For the most part there was little difference across the building spaces for these compounds, and little difference from the ambient air measurement. The single exception to this observation is methylene chloride that appears to increase by about a factor of ten indoors. It is possible that this compound is in use as a cleaning solvent, or it may be present in computer equipment or other supplies. Methylene chloride is also used as a spot remover in dry cleaning processes and may be carried into the building on occupant clothing. The levels of this compound were low relative to health standards $\left(400 \mu \mathrm{g} \mathrm{m}^{-3}\right.$, $24 \mathrm{~h}$, OEHHA 2001).

\section{Plant materials, wood materials, cleaners}

A small increase of a-pinene was observed in the building, particularly on the $5^{\text {th }}$ floor. The source of this compound could be wood products, the indoor plants, cleaning supplies, or air freshener. The concentration of this compound was extremely low.

\section{Plasticizers}

Only trace levels of the plasticizers TXIB (2,2,4-trimethylpentanediol diisobutyrate) and diethylphtalate were observed in the building. TXIB is used to increase the flexibility of 
vinyl products. The measurements likely confirm that very little of these products are present in the PBC. Similarly, diethylphtalate is a compound used to soften plastics. These measurements likely confirm that very little of these products are present in the PBC, however there is a suggestion of a source in the building.

\section{Particle Concentrations}

Indoor and outdoor particle concentrations $\left(\mathrm{PM}_{2.5}\right.$, particles less than 2.5 micrometers in aerodynamic diameter) measured in the afternoon of January 1 are shown in Figure 7. Average ( \pm standard deviation) $\mathrm{PM}_{2.5}$ concentrations were $380 \pm 49$ and $26 \pm 8 \mu \mathrm{g} \mathrm{m}^{-3}$ at the outdoor and indoor measurement sites, respectively. This translates to an indoor/outdoor ratio of $6.8 \%$.

\section{Temperature, Relative Humidity and Indoor Carbon Dioxide Concentrations}

Table 3 lists indoor and outdoor $\mathrm{T}$ and $\mathrm{RH}$ concentrations and $\mathrm{CO}_{2} 10$ minute average spot measurements. Greenhouse temperatures were lower and RH levels were higher throughout the study day.

Ambient $\mathrm{CO}_{2}$ concentration on the roof was $380 \mathrm{ppm}$. The outlet of the greenhouse was slightly higher at $385 \mathrm{ppm}$. Fifth floor concentrations at the AHU return was $500 \mathrm{ppm}$, while the $3^{\text {rd }}$ floor concentration was about $600 \mathrm{ppm}$. It was not possible to discern the amount by which the plants in the building were lowering the $\mathrm{CO}_{2}$ concentration, primarily because of the low occupancy on January 1 .

\section{Discussion}

\section{Are plants reducing indoor VOC and aldehydes?}

Table 4 shows relative differences in VOC and aldehyde concentrations at different points within the $\mathrm{PBC}$ as air flows through the building. The relative concentration differences percentages are calculated as follows.

Relative Difference $=\frac{\text { Upstream Concentration }- \text { Downstream Concentration }}{\text { Upstream Concentration }} \times 100$

Note that for compounds where measurements were below the LOQ the relative difference may be an artifact of imprecision of measurement rather than a reflection of real differences. These values should be interpreted carefully. In Table 4 the compounds which display relative reductions between two zones are shaded a tan color, while those with relative increase of factors of tens are shaded light green, and those with relative increases by factors of 100 are shaded red.

The HVAC inlet to the building which includes an air washer and filtration showed a reduction of all measured VOCs and aldehydes with the exception of octanal, 1,4dichlorobenze, decamethylpentasiloxane, phenol, TXIB and diethylpthalate. The reductions were ranged from $4 \%$ (chloroform) to $100 \%$ for 2-butoxyethanol, $\mathrm{d}$ limonene, trichloroethylene, and a-pinene. The plasticizer concentrations increased 
140\% (TXIB) and 320\% (diethylpthalate) as the air moved from outside into the greenhouse.

VOC concentrations all increased (except octanal, -5\%, TXIB -53\%, and diethlylpthalate $-80 \%$ ) as the air was transmitted through the greenhouse. The concentration of the odorous compounds hexanal and nonanal increased by $68 \%$ and $110 \%$, respectively in the greenhouse. Most other compounds showed modest increases on the order of $10 \mathrm{~s}$ of percentage points, although styrene concentrations increased by almost a factor of 7 in the greenhouse.

With only a few exceptions (relatively small reductions of benzaldehyde, benzene, carbon tetrachloride, and ethylbenzene), VOC and aldehyde concentrations increased as the ventilation air moved from the greenhouse into the occupied building spaces. Increases between the average indoor concentrations and the greenhouse air exit ranged from $6 \%$ for toluene to a factor of 120 for the cleaning solvent 2-butoxyethanol. The cleaning solvent d-limonene increased by a factor of 56 , methylene chloride increased by a factor of 11 , and a-pinene by a factor of 64 . Diethylpthalate increased by a factor of 21 . Odorous compounds hexanal, nonanal, and octanal all increased by factors of two to four, as did the irritating and carcinogenic compound formaldehyde. The deodorant 1,4-dichlorobenzene concentration increased by over a factor of six.

The concentration of the VOCs and aldehydes in the HVAC exhaust stream was in only a single case lower than the incoming air (octanal), where it was zero in the exhaust. D-limonene was 19 fold higher in the exhaust than the intake, 1,4dichlorobenzen was 76 fold higher, and diethylpthalate increased 17 fold. Concentrations in the exhaust vs. greenhouse tended to be higher than the comparison to the ambient air - this is due the observed decrease at the intake relative to the greenhouse - possibly the benefit of the air washer. Overall, exhaust concentrations exceeded that supplied to the zones containing plants by small to large multiples.

The concept that the building air is scrubbed clean of gaseous air contaminants by the plants is not supported by the data. This being said, it is not known what the building IAQ would be without the plants.

\section{Comparison of VOC and Aldehyde Concentration with other Office Buildings}

Table 5 provides a comparison between the measured indoor VOC and aldehyde concentrations in the PBC and those measured in a survey of office buildings in the United States (U.S.). From 1994 to 1998 the U.S. Environmental Protection Agency (EPA) conducted the Building Assessment and Survey Evaluation (BASE) Study of 100 randomly selected office buildings in the continental U.S. (Womble et al 1996). The data in Table 5 are summary statistics of measurements taken from the BASE study (Apte and Erdmann, 2002). Note that not all of the VOCs measured in the PBC were studied in the BASE study, and vise-versa. The BASE study did not measure all of the listed compounds in all 100 buildings as can be seen from the Table. 
Compounds for which the PBC had more that a factor of two greater indoor concentrations than the BASE Study mean are 1,4-dichlorobenzene, methylene chloride (also greater than the BASE Study maximum), and TXIB. The measured PBC formaldehyde and acetaldehyde levels were both above the mean BASE Study levels by more than one standard deviation.

Compounds for which the PBC had one half or less of the concentration of the BASE Study indoor concentrations included 2-butoxyethanol, acetone, d-limonene, phenol, and styrene. Both 2-butoxyethanol and d-limonene are cleaning agents that may be used less frequently in the PBC than in the U.S. office buildings.

The compound measured that is of greatest concern is formaldehyde, as discussed above, which has an 8-hr average REL of $9 \mu \mathrm{g} \mathrm{m}^{-3}$. The average across the measured spaces in Floors 5 and 3 was $28 \pm 1.4 \mu \mathrm{g} \mathrm{m}^{-3}$. However, the observed formaldehyde concentrations fall within levels that have been recorded in U.S. office buildings ( 3.4 to $45 \mu \mathrm{g} \mathrm{m}^{-3}$ ).

The observed levels of odorous compounds hexanal, nonanal, and octanal may detract from perceived air quality in the $\mathrm{PBC}$, as the observed concentrations exceed document odor thresholds. However the levels may not be high enough to be irritating to occupants.

The presence of 1,4-dichlorobenzene in the ambient and greenhouse air suggests that some short circuiting of ventilation exhaust back into the building. It may also be possible that some leakage across the heat recovery wheel is slightly contaminating the fresh intake air.

\section{Measured Particle Concentrations}

The removal of ambient particulate matter by the PBC rooftop air handler, the particle loss mechanisms in the air transit through greenhouse and ducting into the building, and the re-circulating filtration of air by the floor level AHUs appears to be rather successful. Indoor $\mathrm{PM}_{2.5}$ was reduced to $26 \pm 8 \mu \mathrm{g} \mathrm{m}^{-3} 7 \%$ of outdoor levels. There are no indoor standards for $\mathrm{PM}_{2.5}$, but the World Health Organization has set the outdoor 24 hour standards at $25 \mu \mathrm{g} / \mathrm{m}^{3}$, and the annual PM2.5 standard at 10 $\mu \mathrm{g} / \mathrm{m}^{3}$ (WHO 2000). Considering the extremely high outdoor $\mathrm{PM}_{2.5}$ levels in New Delhi, the protective environment provided by the PBC is phenomenal.

\section{Other Air Contaminants of Concern}

This one-day study did not measure all possible air contaminants in the PBC or surrounding outdoor air. Ozone is an important air contaminant that was not measured, that may have a bearing on IAQ in the building. On January 1 the ozone level in the ambient air was likely around it's lowest for the year as its formation is dependent on radiation from the sun, and it varies with the seasons. However, during other times of the year, ozone entrained into the building could have a 
significant impact on IAQ as it reacts with d-limonene, a-pinene, and other alkene compounds. Future work should include a study of ozone entry into the building.

\section{Conclusions}

Indoor environmental quality in the $\mathrm{PBC}$, as measured by the VOC and aldehyde species measured in this study, is very similar to that measured in many office buildings in the United States. Given the extreme air pollution levels in the outdoor environment of New Delhi, this is an achievement.

The purpose of this study was to investigate the benefits of using indoor plants to clean the office building air. Having done this, there appears to be no strong evidence that the plants play a special role in cleaning the PBC air. The air washer and filtration array at the intake of the building's HVAC system appears to substantially reduce incoming air contaminants. Once the ventilation air enters the building, the concentration of common VOCs and aldehydes appear to rise incrementally until the air is exhausted. The key contaminant of concern in the PBC is formaldehyde. The deodorant used in the rest rooms raises indoor levels of 1,4dichlorobenzne to atypically high concentrations. Methylene chloride appears to have an abundant source in the PBC.

\section{Acknowledgements}

This work was sponsored by the Assistant Secretary for Energy Efficiency and Renewable Energy, Office of Building Technology, State, and Community Programs, of the U.S.Department of Energy under Contract No. DE-AC02-05CH11231. Its contents are solely the responsibility of the authors and do not necessarily represent the official views of the US DOE. The authors would like to thank Randy Maddalena and William Fisk for their reviews of this paper, Marion Russell for analysis of the VOC samples, and Doug Sullivan for organization and shipping of the equipment used in this project.

\section{References}

MG Apte and CA Erdmann. 2002. Associations of Indoor Carbon Dioxide Concentrations, VOCs, and Environmental Susceptibilities with Mucous Membrane and Lower Respiratory Sick Building Syndrome Symptoms in the BASE Study: Analyses if the 100 Building Dataset, LBNL-51570, Lawrence Berkeley National Laboratory, University of California, Berkeley, CA 94720.

ASTM. Standard Test Method for the Determination of Formaldehyde and Other Carbonyl Compounds in Air; ASTM Test Method D-5197-92; American Society for Testing and Materials (ASTM):West Conshohocken, PA, 1992.

Cometto-Muñiz JE, Abraham MH. 2010. Odor Detection by Humans of Lineal Aliphatic Aldehydes and Helional as Gauged by Dose-Response Functions," Chem. Senses. Online publication ahead of print.

OEHHA. 2001. Chronic Toxicity Summary - Methylene Chloride, Office of Environmental Health Hazards Assessment, California Environmental Protection 
Agency, Sacramento CA. http://www.oehha.org/air/chronic_rels/AllChrels.html OEHHA. 2008. Chronic Toxicity Summary - Formaldehyde, Office of Environmental Health Hazards Assessment, California Environmental Protection Agency, Sacramento CA. http://www.oehha.org/air/chronic rels/AllChrels.html

USEPA. 1999a Determination of Volatile Organic Compounds in Ambient Air Using Active Sampling onto Sorbent Tubes: Compendium Method TO-17; Office of Research and Development, U.S. Environmental Protection Agency: Research Triangle Park, NC, 1996.

USEPA. 1999b Determination of Formaldehyde in Ambient Air Using Adsorbent Cartridge Followed by High Performance Liquid Chromatography (HPLC) [Active Sampling Methodology]: Compendium Method TO-11A; Office of Research and Development, U.S. Environmental Protection Agency: Research Triangle Park, NC, 1996.

Womble SE, Ronca EL, Girman JR, et al. 1996. "Developing Baseline Information on Buildings and Indoor Air Quality (Base '95)," In IAQ 96/Paths to Better Building Environments/Health Symptoms in Building Occupants, American Society of Heating Refrigeration and Air-conditioning Engineers, Atlanta.

WHO. 2000. Air quality guidelines for Europe, 2nd ed. Copenhagen, World Health Organization Regional Office for Europe, 2000 (WHO Regional Publications, European Series No. 91). 


\section{Tables}

Table 1. Target List of Volatile Organic Chemicals

\begin{tabular}{lllrl}
\hline Chemical & Class & CAS & BP & method \\
\hline Phenol & alcohol & $108-95-2$ & 182 & TD-GC/MS \\
Formaldehde & aldehyde & $50-00-0$ & -19 & DNPH/HPLC \\
Acetaldehyde & aldehyde & $75-07-0$ & 20 & DNPH/HPLC \\
n-Hexanal & aldehyde & $66-25-1$ & 128 & TD-GC/MS \\
Octanal & aldehyde & $124-13-0$ & 174 & TD-GC/MS \\
Benzaldehyde & aldehyde & $100-52-7$ & 179 & TD-GC/MS \\
Nonanal & aldehyde & $124-19-6$ & 195 & TD-GC/MS \\
Decanal & aldehyde & $112-31-2$ & 209 & TD-GC/MS \\
n-Hexane & alkane & $110-54-3$ & 69 & TD-GC/MS \\
Benzene & aromatic & $71-43-2$ & 80 & TD-GC/MS \\
Toluene & aromatic & $108-88-3$ & 111 & TD-GC/MS \\
Ethylbenzene & aromatic & $100-41-4$ & 136 & TD-GC/MS \\
m-Xylene & aromatic & $108-38-3$ & 139 & TD-GC/MS \\
p-Xylene & aromatic & $106-42-3$ & 139 & TD-GC/MS \\
O-Xylene & aromatic & $95-47-6$ & 143 & TD-GC/MS \\
Styrene & aromatic & $100-42-5$ & 145 & TD-GC/MS \\
Naphthalene & aromatic & $91-20-3$ & 218 & TD-GC/MS \\
& Cl & & & \\
1,4-dichlorobenzene & Aromatic & $106-46-7$ & 174 & TD-GC/MS \\
TXIB & ester & $6846-50-0$ & 280 & TD-GC/MS \\
Diethylphthalate & ester & $84-66-2$ & 298 & TD-GC/MS \\
& glycol & & & \\
2-Butoxyethanol & ether & $111-76-2$ & 171 & TD-GC/MS \\
Methylene Chloride & halo & $75-09-2$ & 40 & TD-GC/MS \\
Chloroform & halo & $67-66-3$ & 62 & TD-GC/MS \\
Carbon & & & & \\
Tetrachloride & halo & $56-23-5$ & 77 & TD-GC/MS \\
Trichloroethylene & halo & $79-01-6$ & 87 & TD-GC/MS \\
Tetrachloroethylene & halo & $127-18-4$ & 121 & TD-GC/MS \\
Acetone & ketone & $67-64-1$ & 56 & DNPH/HPLC \\
D-5 Siloxane & misc. & $541-02-6$ & 210 & TD-GC/MS \\
a-Pinene & terpene & $7785-70-8$ & 155 & TD-GC/MS \\
d-Limonene & terpene & $5989-27-5$ & 177 & TD-GC/MS \\
\hline a 2,2,4-Trimethylpentanediol diisobutyrate & & \\
& & & &
\end{tabular}


Table 2. Measured Volatile Organic Compounds (VOCs) and Aldehyde concentrations indoors and outdoors at the PBC. The limits of quantitation (LOQ) for the measurements of these compounds are also provided.

\begin{tabular}{|c|c|c|c|c|c|c|c|c|c|c|c|c|}
\hline $\begin{array}{c}\text { VOCs } \\
\text { Measured }(\mu \mathrm{g} / \mathrm{m} 3)\end{array}$ & $\mathrm{LOQ}^{\mathrm{c}}$ & Ambient & $\begin{array}{l}\text { GH } \\
\text { In }\end{array}$ & $\begin{array}{l}\text { GH Out } \\
\text { (AM) }\end{array}$ & $\begin{array}{l}\text { GH Out } \\
\text { (PM) }\end{array}$ & $\begin{array}{l}\text { Rm } 311 \\
\text { Supply }\end{array}$ & $\begin{array}{l}\text { Rm.510 } \\
\text { Supply }\end{array}$ & $\begin{array}{l}\text { Rm.311 } \\
\text { Rtn. }\end{array}$ & $\begin{array}{c}\text { Rm } 510 \\
\text { Rtn. }\end{array}$ & $\begin{array}{c}\text { Flr. } 3 \\
\text { AHU Rtn. }\end{array}$ & $\begin{array}{c}\text { Flr. } 5 \\
\text { AHU Rtn. }\end{array}$ & $\begin{array}{l}\text { Bld. } \\
\text { Exh. }\end{array}$ \\
\hline \multicolumn{13}{|c|}{ Carbonyl } \\
\hline Acetaldehyde & 0.2 & 6.9 & 4.4 & 4.1 & 6.0 & 12 & 13 & 12 & 13 & 12 & 11 & 11 \\
\hline Acetone & 0.2 & 10 & 6.8 & 6.5 & 9.7 & 22 & 26 & 24 & 26 & 23 & 22 & 18 \\
\hline Benzaldehyde & 0.7 & 2.2 & 2.6 & 3.3 & 3.6 & 2.3 & 2.5 & 2.1 & 2.3 & 2.0 & 2.0 & 2.5 \\
\hline Formaldehyde & 0.4 & 6.2 & 4.5 & 3.9 & 8.5 & 27 & 27 & 30 & 29 & 29 & 25 & 20 \\
\hline Hexanal & 2.4 & 0.8 & 0.5 & 1.1 & 0.6 & 4.5 & 4.1 & 4.6 & 3.7 & 3.2 & 2.6 & 3.4 \\
\hline Nonanal & 2.1 & 1.2 & 0.6 & 1.4 & 1.1 & 4.3 & 3.8 & 3.7 & 3.5 & 3.1 & 2.6 & 2.2 \\
\hline Octanal & 2.4 & 0.3 & 0.3 & 0.2 & 0.3 & 1.6 & 1.6 & 1.6 & 1.5 & 1.3 & 1.2 & ND \\
\hline \multicolumn{13}{|c|}{ Cleaning solvents } \\
\hline 2-butoxyethanol & 1.7 & 1.3 & ND & ND & ND & 1.5 & 2.7 & 2.0 & 2.4 & 1.4 & 1.5 & 1.5 \\
\hline Benzene & 4.8 & 6.6 & 4.6 & 5.1 & 11 & 5.9 & 6.9 & 6.5 & 6.1 & 6.4 & 4.7 & 12 \\
\hline d-limonene & 0.4 & 0.1 & 0.0 & 0.0 & 0.2 & 2.1 & 13 & 2.1 & 11 & 2.2 & 4.5 & 2.9 \\
\hline n-hexane & 5.6 & 4.5 & 3.2 & 4.0 & 9.2 & 5.7 & 4.8 & 6.8 & 3.5 & 7.7 & 3.4 & 14 \\
\hline Naphthalene & 0.5 & 0.5 & 0.3 & 0.3 & 0.8 & 4.3 & 4.2 & 4.1 & 4.1 & 3.2 & 3.5 & 3.1 \\
\hline Toluene & 0.4 & 48 & 18 & 18 & 59 & 41 & 40 & 41 & 34 & 53 & 33 & 120 \\
\hline Trichloroethylene & 1.3 & 0.2 & ND & ND & ND & 0.3 & 0.4 & 0.3 & 0.3 & 0.3 & 0.2 & 0.6 \\
\hline \multicolumn{13}{|c|}{ Bathroom products } \\
\hline 1,4-dichlorobenzene & 0.3 & 2.2 & 3.9 & 4.8 & 6.0 & 25 & 65 & 23 & 56 & 21 & 49 & 170 \\
\hline \multicolumn{13}{|c|}{ Office products, supplies, materials, occupants, Ambient } \\
\hline Carbon tetrachloride & 5.2 & 0.2 & 0.4 & 0.3 & 0.7 & 0.6 & 0.5 & 0.5 & 0.5 & 0.2 & 0.3 & 0.6 \\
\hline Chloroform & 7.4 & 0.4 & 0.4 & 0.3 & 0.7 & 1.5 & 1.0 & 1.4 & 0.8 & 1.2 & 0.9 & 1.3 \\
\hline D5 siloxane & 1.2 & 0.1 & 0.1 & 0.1 & 0.1 & 0.6 & 0.8 & 0.5 & 0.8 & 0.5 & 0.5 & 0.9 \\
\hline Ethylbenzene & 0.4 & 4.6 & 2.4 & 2.2 & 7.2 & 5.1 & 4.5 & 4.7 & 4.1 & 5.5 & 3.7 & 11 \\
\hline M/p-xylene & 0.4 & 9.9 & 4.6 & 4.3 & 15 & 12 & 10 & 10 & 9.1 & 13 & 8.1 & 25 \\
\hline Methylene chloride & 4.0 & 1.3 & 0.9 & 1.1 & 3.0 & 33 & 23 & 36 & 14 & 23 & 19 & 13 \\
\hline o-xylene & 0.5 & 4.7 & 2.3 & 2.1 & 6.8 & 5.2 & 4.5 & 5.2 & 4.3 & 5.7 & 3.7 & 11 \\
\hline Phenol & 6.7 & 0.3 & 0.5 & 0.9 & ND & 0.9 & 1.0 & 0.9 & 0.9 & 0.9 & 0.8 & 0.8 \\
\hline Styrene & 0.6 & 0.4 & 0.0 & 0.0 & 0.7 & 0.8 & 0.8 & 0.9 & 0.8 & 0.9 & 0.7 & 1.5 \\
\hline Tetrachloroethylene & 0.6 & 0.7 & 0.6 & 0.5 & 0.9 & 1.3 & 1.3 & 1.5 & 1.1 & 0.9 & 0.8 & 2.0 \\
\hline \multicolumn{13}{|c|}{ Plant materials, wood materials, cleaners } \\
\hline$\alpha$-pinene & 0.7 & 0.6 & ND & ND & ND & 0.7 & 2.2 & 0.7 & 2.0 & 0.6 & 1.2 & 0.8 \\
\hline \multicolumn{13}{|c|}{ Plasticizers } \\
\hline TXIB $^{\mathrm{a}}$ & 1.4 & 0.0 & 0.1 & ND & ND & 0.2 & 0.1 & 0.2 & 0.1 & 0.2 & 0.1 & 0.1 \\
\hline Diethylphthalate & 0.4 & 0.0 & 0.1 & ND & ND & 0.4 & 0.4 & 0.5 & 0.4 & 0.5 & 0.3 & 0.4 \\
\hline
\end{tabular}

a 2,2,4-trimethylpentanediol diisobutyrate, ${ }^{b}$ decamethylcyclopentasiloxane; ' Limit of Quantitation

ND $=$ not detected or less than minimum detection level 
Table 3. Measured Carbon Dioxide $\left(\mathrm{CO}_{2}\right)$, Temperature (T), and Relative Humidity (RH)

\begin{tabular}{|c|c|c|c|c|c|}
\hline $\begin{array}{l}\text { Location } \\
\text { Ambient PM monitoring loc }\end{array}$ & Start & Stop & $\mathrm{CO}_{2}(\mathrm{ppm})$ & $\mathrm{T}\left({ }^{\circ} \mathrm{C}\right)$ & $\mathrm{RH}(\%)$ \\
\hline on roof & $15: 45$ & 15:56 & 381 & & \\
\hline Greenhouse inlet & $16: 34$ & $16: 47$ & 385 & $17.5 \pm 0.1$ & $72 \pm 0$ \\
\hline Greenhouse outlet & $16: 01$ & $16: 30$ & 391 & $17.2 \pm 0.2$ & $71 \pm 0$ \\
\hline Rm 311 & $15: 18$ & $15: 28$ & 643 & $22.9 \pm 0.1$ & $48 \pm 0$ \\
\hline AHU 3rd floor & $15: 31$ & $15: 41$ & 601 & $23.1 \pm 0.0$ & $48 \pm 0$ \\
\hline Rm 506 & 15:04 & 15:15 & 552 & $24.3 \pm 0.1$ & $44 \pm 0$ \\
\hline AHU 5th floor & $14: 52$ & 15:02 & 495 & $24.3 \pm 0.0$ & $44 \pm 0$ \\
\hline Building exhuast & $16: 52$ & $\begin{array}{r}17: 03 \\
\text { All Day }\end{array}$ & 476 & & \\
\hline Greenhouse & & & & $19 \pm 3.6$ & $66 \pm 9$ \\
\hline RM 506 & & & & $23 \pm 1.4$ & $47 \pm 3$ \\
\hline RM 311 & & & & $22 \pm 1.0$ & $50 \pm 3$ \\
\hline
\end{tabular}


Table 4. Relative differences (percent) between VOC and aldehyde concentrations between different PBC HVAC domains

\begin{tabular}{|c|c|c|c|c|c|c|c|}
\hline Compound/location $^{\mathrm{a}}$ & $\begin{array}{c}\mathrm{GH}_{\text {in }} \mathrm{vs} \\
\text { OUT } \\
(\%)\end{array}$ & $\begin{array}{c}\mathrm{GH}_{\text {in }} \mathrm{vs} \\
\mathrm{Gh}_{\text {out }} \\
(\%)\end{array}$ & $\begin{array}{c}\text { FLR5 vs } \\
\text { GH }_{\text {out }} \\
(\%)\end{array}$ & $\begin{array}{c}\text { FL3 vs } \\
\mathrm{GH}_{\text {out }} \\
(\%)\end{array}$ & $\begin{array}{c}\text { Indoor vs } \\
\mathrm{GH}_{\text {out }} \\
(\%)\end{array}$ & $\begin{array}{c}\text { Exh vs } \\
\mathrm{GH}_{\text {in }} \\
(\%)\end{array}$ & $\begin{array}{l}\text { Exh vs } \\
\text { OUT } \\
(\%)\end{array}$ \\
\hline \multicolumn{8}{|c|}{ Carbonyl } \\
\hline acetaldehyde & -36 & 14 & 140 & 1 & 140 & 140 & 54 \\
\hline acetone & -33 & 19 & 210 & 190 & 200 & 170 & 76 \\
\hline benzaldehyde & 19 & 32 & -34 & -38 & -36 & -4 & 14 \\
\hline formaldehyde & -28 & 38 & 330 & 370 & 350 & 340 & 210 \\
\hline hexanal & -37 & 68 & 310 & 390 & 350 & 580 & 330 \\
\hline nonanal & -50 & 110 & 170 & 200 & 180 & 260 & 80 \\
\hline octanal & 8 & -5 & 400 & 420 & 410 & -100 & -100 \\
\hline \multicolumn{8}{|c|}{ Cleaning solvents } \\
\hline 2-butoxyethanol & -100 & - & 14000 & 10000 & 12000 & - & 19 \\
\hline benzene & -30 & 73 & -27 & -22 & -24 & 170 & 86 \\
\hline d-limonene & -100 & - & 9200 & 1900 & 5600 & - & 1900 \\
\hline n-hexane & -30 & 110 & -41 & 2 & -20 & 340 & 210 \\
\hline naphthalene & -31 & 80 & 580 & 560 & 570 & 860 & 560 \\
\hline toluene & -63 & 110 & -7 & 18 & 6 & 570 & 150 \\
\hline trichloroethylene & -100 & - & - & - & - & - & 210 \\
\hline Bathroom products & & & & & & & \\
\hline 1,4-dichlorobenzene & 76 & 40 & 950 & 330 & 640 & 4300 & 7600 \\
\hline \multicolumn{8}{|c|}{ Office products, supplies, materials, occupants, Ambient } \\
\hline carbon tetrachloride & 71 & 19 & -14 & -13 & -14 & 39 & 140 \\
\hline chloroform & -4 & 37 & 80 & 180 & 130 & 260 & 250 \\
\hline decamethylcyclopentasiloxane & 61 & -53 & 940 & 660 & 800 & 480 & 830 \\
\hline ethylbenzene & -48 & 96 & -13 & 8 & -2 & 350 & 130 \\
\hline $\mathrm{m} / \mathrm{p}$-xylene & -54 & 110 & -5 & 21 & 8 & 450 & 160 \\
\hline methylene chloride & -32 & 130 & 830 & 1400 & 1100 & 1400 & 920 \\
\hline o-xylene & -52 & 98 & -7 & 20 & 7 & 370 & 120 \\
\hline phenol & 53 & -3 & 100 & 100 & 100 & 83 & 180 \\
\hline styrene & -88 & 680 & 110 & 130 & 120 & 3000 & 260 \\
\hline tetrachloroethylene & -24 & 26 & 55 & 79 & 67 & 270 & 180 \\
\hline \multicolumn{8}{|c|}{ Plant materials, wood materials, cleaners } \\
\hline a-pinene & -100 & - & 9400 & 3300 & 6400 & - & 42 \\
\hline \multicolumn{8}{|c|}{ Plasticizers } \\
\hline $\mathrm{TXIB}^{\mathrm{b}}$ & 140 & -53 & 159 & 300 & 230 & 50 & 260 \\
\hline diethylphthalate & 320 & -80 & 1900 & 2300 & 2100 & 340 & 1700 \\
\hline
\end{tabular}

aLocations: $\mathrm{GH}_{\mathrm{in}}=$ Inlet to greenhouse; $\mathrm{GH}_{\text {out }}=$ outlet from greenhouse; Indoor = average of all indoor locations; Exh = building exhaust.; ${ }^{\text {2 } 2,2,4-T r i m e t h y l p e n t a n e d i o l ~ d i i s o b u t y r a t e ~}$

Shading code: Tan $=$ negative/relative reduction of concentration; light green $=$ rel. increases by factors of ten; red $=$ rel. increases by factors of 100 
Table 5. Comparison of select PBC VOC and Aldehyde measurements to those in the 100 Building U.S. EPA BASE Study.

\begin{tabular}{|c|c|c|c|c|c|c|c|c|}
\hline \multirow[b]{2}{*}{ Compound } & \multicolumn{2}{|c|}{ PBC Indoors } & \multicolumn{6}{|c|}{ U.S. EPA BASE Study Indoor-outdoor Concentrations } \\
\hline & $\begin{array}{c}\text { Mean } \\
\left(\mu \mathrm{g} \mathrm{m}^{-3}\right)\end{array}$ & $\begin{array}{l}\text { Std Dev } \\
\left(\mu g \mathrm{~m}^{-3}\right)\end{array}$ & $\begin{array}{c}\text { Mean } \\
\left(\mu \mathrm{g} \mathrm{m}^{-3}\right)\end{array}$ & $\begin{array}{l}\text { Std Dev } \\
\left(\mu \mathrm{g} \mathrm{m}^{-3}\right)\end{array}$ & $\begin{array}{l}\text { Median } \\
\left(\mu \mathrm{g} \mathrm{m}^{-3}\right)\end{array}$ & $\begin{array}{c}\text { Minimum } \\
\left(\mu \mathrm{g} \mathrm{m}^{-3}\right)\end{array}$ & $\begin{array}{c}\text { Maximum } \\
\left(\mu \mathrm{g} \mathrm{m}^{-3}\right)\end{array}$ & $\begin{array}{c}\text { \# of BASE } \\
\text { Buildings }\end{array}$ \\
\hline 1,4-dichlorobenzene & 40 & 19 & 3.1 & 8.0 & 0.6 & 0.2 & 49.6 & 100 \\
\hline 2-butoxyethanol & 1.9 & 0.53 & 12.3 & 19.2 & 6.4 & 0.1 & 88.6 & 41 \\
\hline a-pinene & 1.2 & 0.70 & 1.1 & 1.1 & 0.6 & 0.2 & 7.9 & 100 \\
\hline acetaldehyde & 12 & 0.70 & 7.9 & 3.8 & 7.3 & 2.0 & 17.4 & 86 \\
\hline acetone & 24 & 1.8 & 55.4 & 33.7 & 45.8 & 14.5 & 221.7 & 87 \\
\hline benzene & 6.1 & 0.75 & 4.9 & 3.9 & 3.6 & 0.9 & 32.5 & 100 \\
\hline methylene chloride & 25 & 8.2 & 2.9 & 1.7 & 2.7 & 1.2 & 16.2 & 87 \\
\hline d-limonene & 5.9 & 5.1 & 11.3 & 17.0 & 6.2 & 0.3 & 130.3 & 100 \\
\hline ethylbenzene & 4.6 & 0.65 & 2.7 & 2.2 & 1.8 & 0.3 & 11.5 & 100 \\
\hline formaldehyde & 28 & 1.9 & 16.3 & 8.4 & 15.0 & 3.4 & 45.0 & 100 \\
\hline hexanal & 3.8 & 0.8 & 5.4 & 3.3 & 4.2 & 1.2 & 14.6 & 41 \\
\hline m \& p-xylenes & 10 & 1.6 & 8.8 & 8.0 & 6.2 & 1.1 & 39.3 & 100 \\
\hline n-hexane & 5.3 & 1.8 & 6.1 & 13.3 & 3.6 & 0.2 & 100.5 & 54 \\
\hline naphthalene & 3.9 & 0.44 & 6.9 & 23.5 & 1.1 & 0.2 & 181.6 & 100 \\
\hline nonanal & 3.5 & 0.6 & 3.6 & 2.4 & 3.0 & 0.8 & 11.9 & 54 \\
\hline o-xylene & 4.8 & 0.73 & 3.1 & 2.7 & 2.2 & 0.4 & 13.7 & 100 \\
\hline phenol & 0.89 & 0.08 & 2.4 & 2.0 & 2.0 & 0.4 & 8.6 & 41 \\
\hline styrene & 0.83 & 0.08 & 1.7 & 2.2 & 0.9 & 0.2 & 14.3 & 100 \\
\hline Toluene & 20 & 7.1 & 17.7 & 33.0 & 9.6 & 2.2 & 314.8 & 100 \\
\hline TXIB $^{a}$ & 15 & 0.05 & 7.2 & 8.3 & 3.6 & 0.2 & 32.2 & 41 \\
\hline
\end{tabular}

a2,2,4-Trimethylpentanediol diisobutyrate 


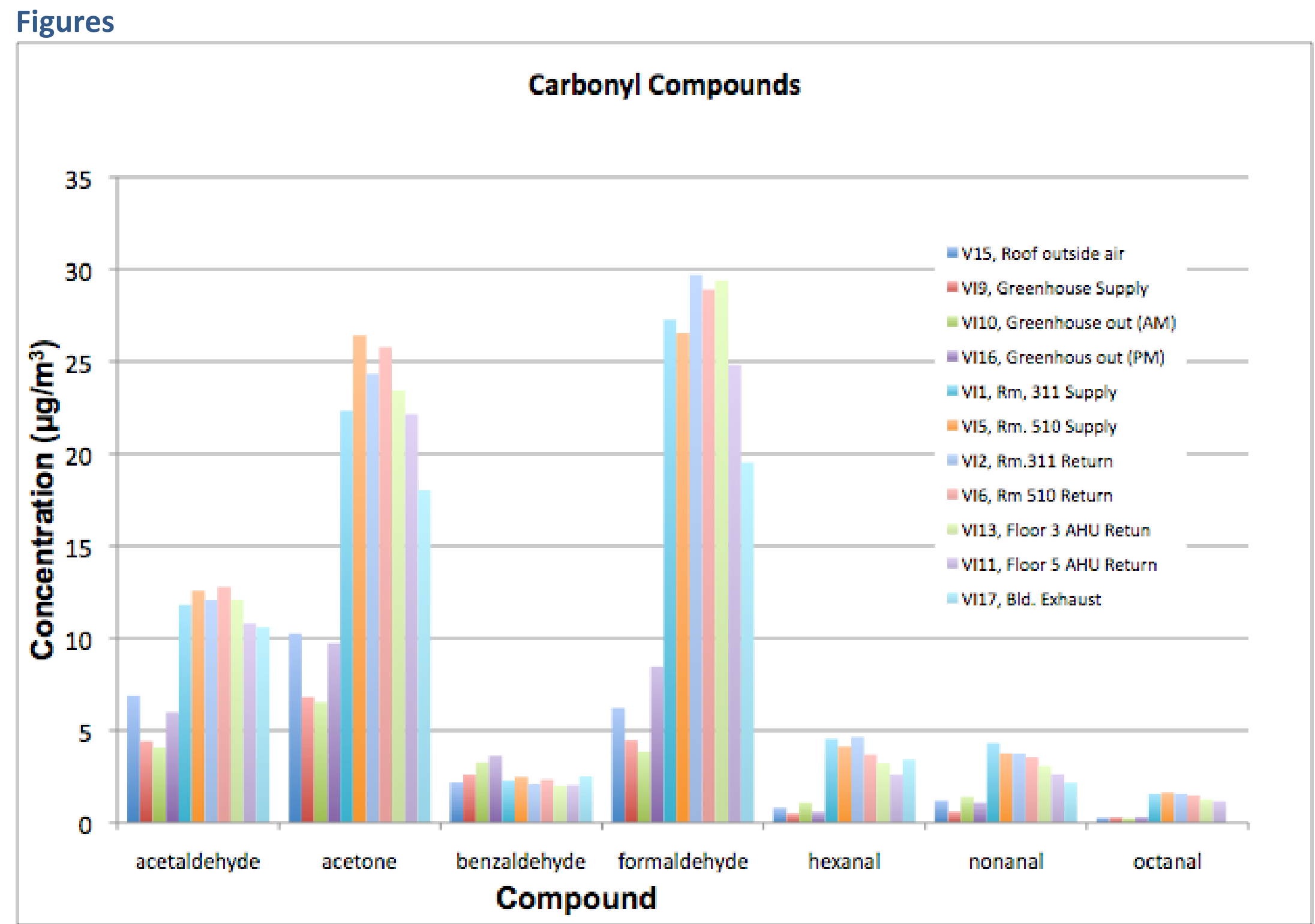

Figure 1. Carbonyl compounds measured at the PBC. 


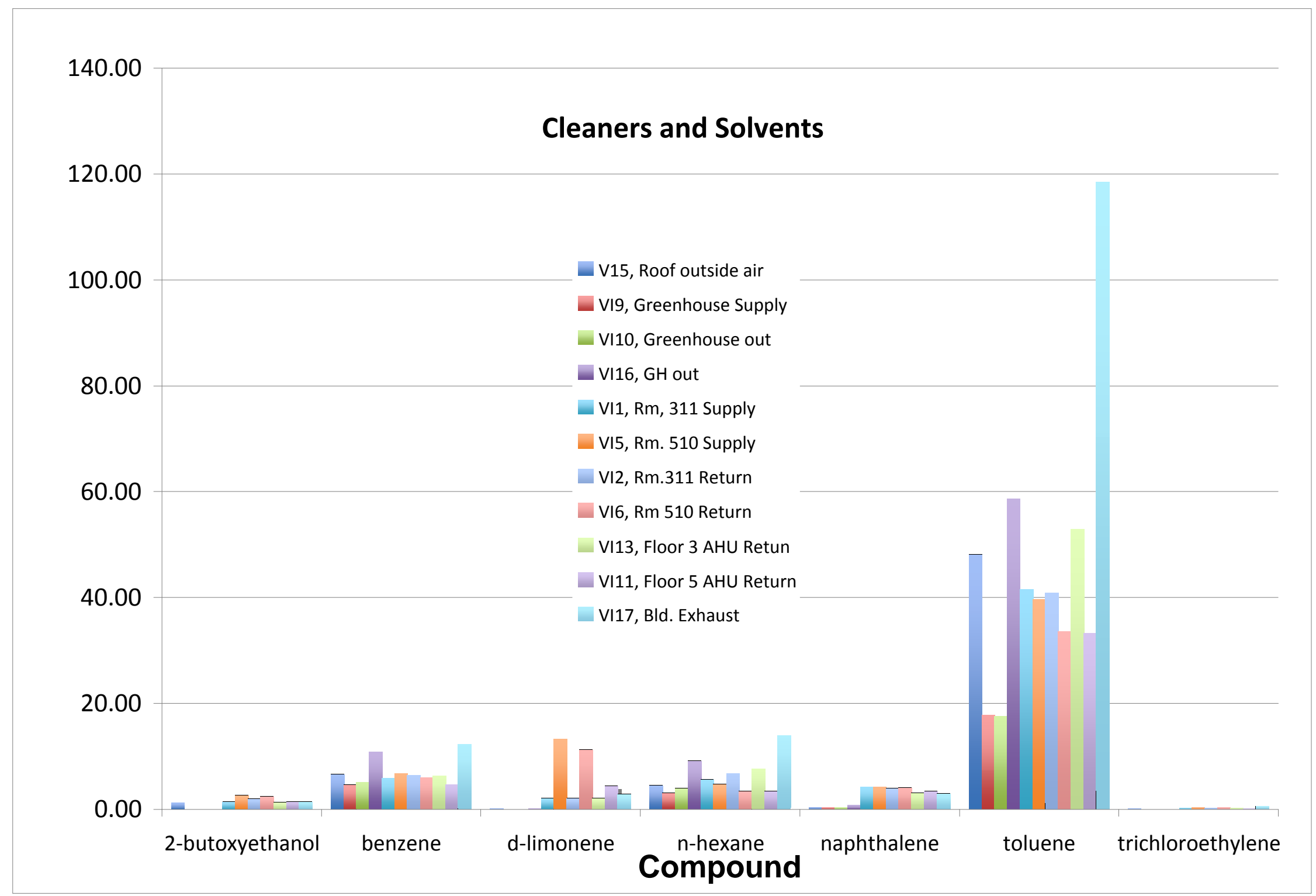

Figure 2. Volatile organic compounds associated with cleaning supplies and solvents measured at the PBC. 


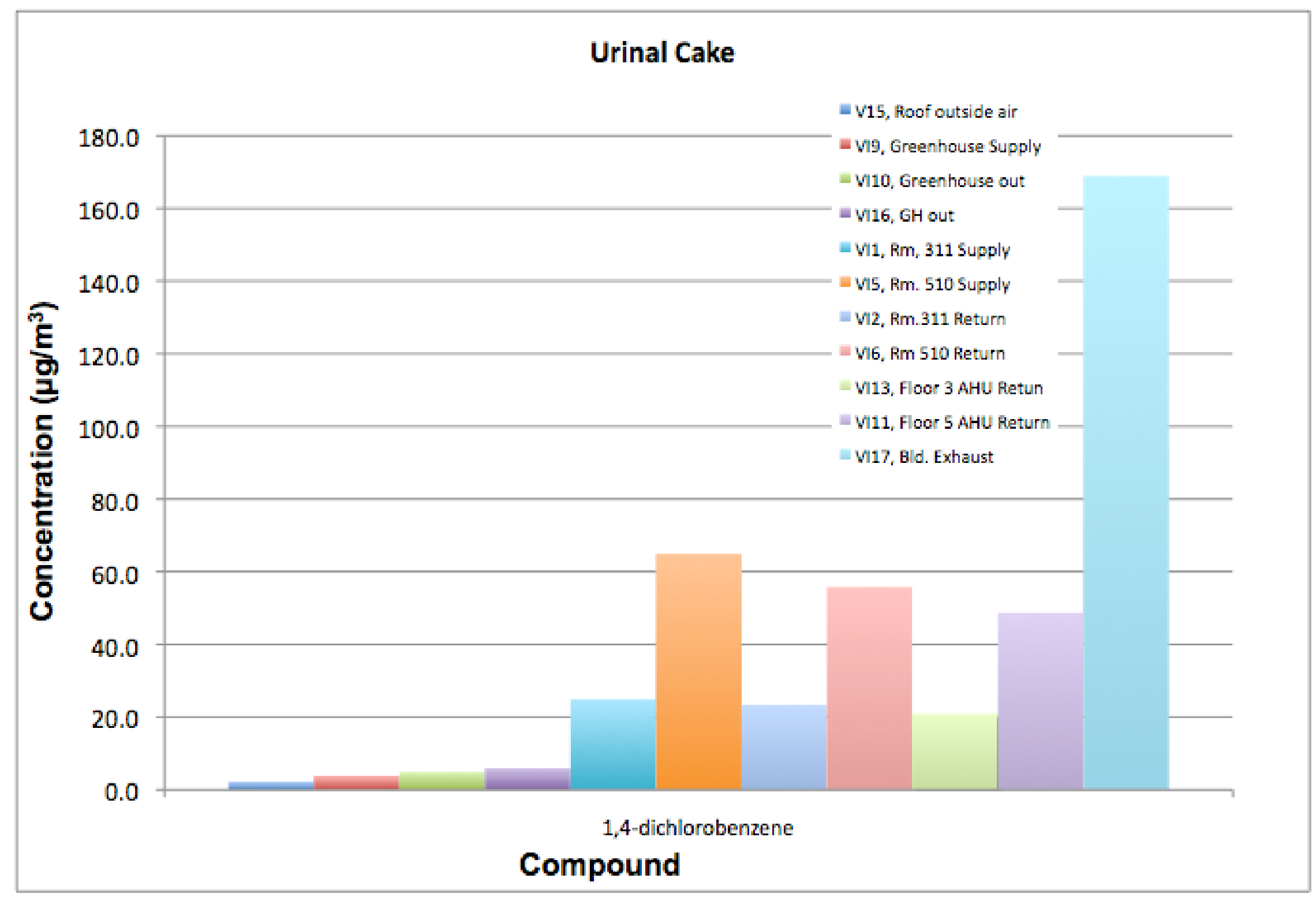

Figure 3. Volatile organic compounds associated with bathroom deodorizer measured at the PBC. 


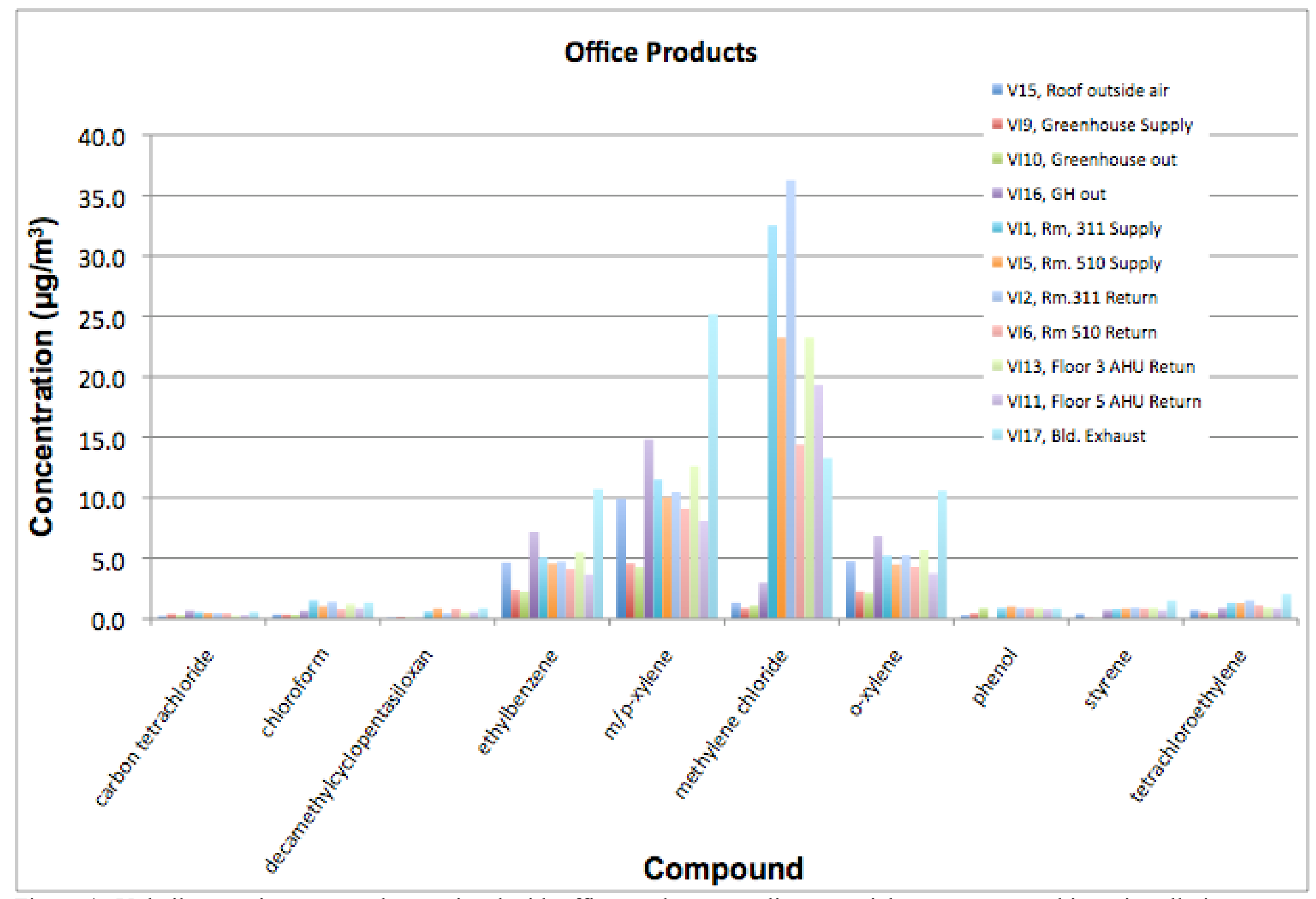

Figure 4. Volatile organic compounds associated with office products, supplies, materials, occupants, ambient air pollution measured at the PBC. 


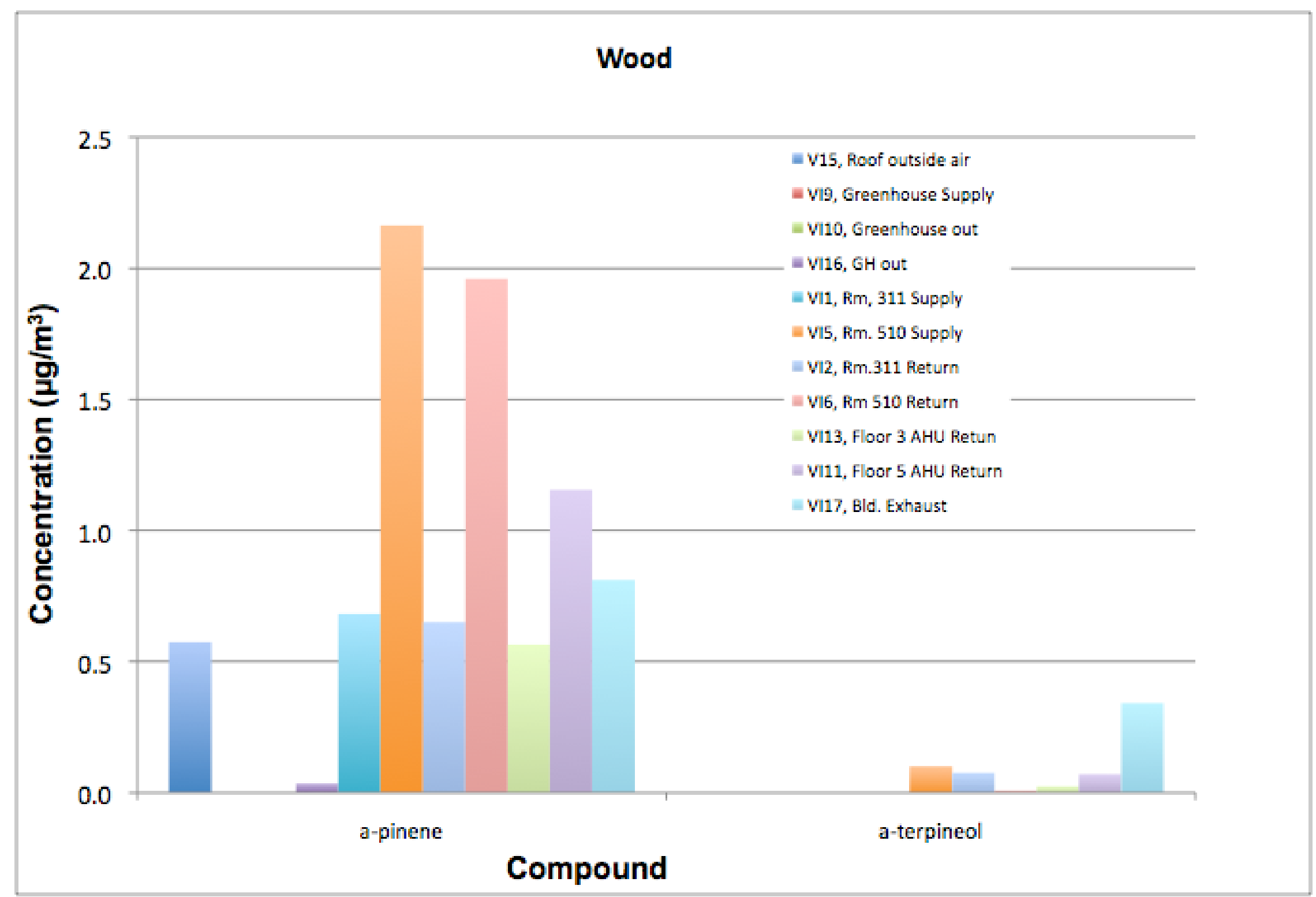

Figure 5. Volatile organic compounds associated with plant materials, wood materials, cleaners measured at the PBC. 


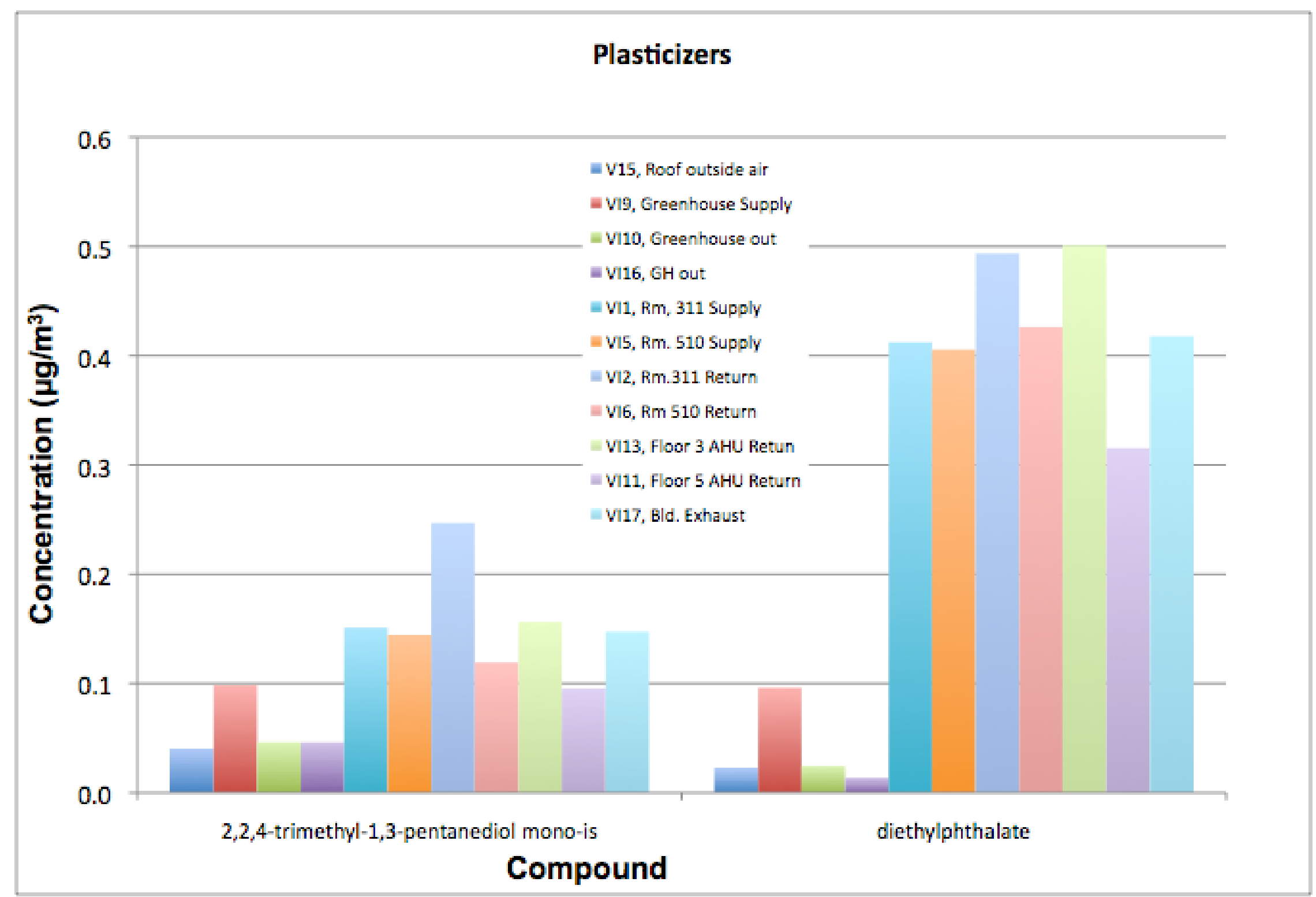

Figure 6. Volatile organic compounds associated with plasticizers in materials measured at the PBC. 




Figure 7. Indoor and outdoor (ambient) $\mathrm{PM}_{2.5}$ particle concentrations at the $\mathrm{PBC}$. 